\title{
Molecular cloning, characterization and expression pattern analysis of a jasmonic acid responsive sesquiterpene synthase gene from Persicaria minor
}

\author{
Chew Jin Kiat ${ }^{1,2}$, Mehdi Farshad Ashraf ${ }^{1,2}$, Muhammad Naeem-Ul-Hassan ${ }^{1}$, Che Radziah Che Mohd \\ Zain $^{1,2}$, Zamri Zainal ${ }^{1,2}$, Ismanizan Ismail ${ }^{* 1,2}$ \\ ${ }^{1}$ School of Biosciences and Biotechnology, Faculty of Science and Technology, Universiti Kebangsaan Malaysia, \\ 43600 Bangi, Selangor, Malaysia \\ ${ }^{2}$ Institute of System Biology, Universiti Kebangsaan Malaysia, Bangi 43600, Selangor, Malaysia
}

*Corresponding author: maniz@ukm.my

\begin{abstract}
Terpenoids represent an important class of plant secondary metabolites, serving as component of plant defense against various biotic and abiotic stresses. A large number of structurally diverse terpenoid compounds have been identified from Persicaria minor $(P$. minor), an aromatic plant native to Malaysia. However, number of studies focusing on the $P$. minor terpenoid metabolism, especially at the genetic level is still very scarce. In the present study, a cDNA sequence (KT192706) from the leaves of $P$. minor, encoding a sesquiterpene synthase (PmSS) gene was successfully cloned. The complete sequence of PmSS comprised of $1724 \mathrm{bp}$ with a $1680 \mathrm{bp}$ open reading frame, corresponding to a deduced protein of 559 amino acids. Under the normal conditions, PmSS gene was found to be differentially expressed in the organs of $P$. minor. Significantly higher expression level of PmSS was recorded in leaves and stems which are, respectively, about 98 folds and 49 folds higher than that in the roots. In addition, the present study has also shown that the expression of PmSS gene was responsive towards the exogenous application of jasmonic acid in all organs of the $P$. minor.
\end{abstract}

Keywords: Sesquiterpene synthase, terpene, Persicaria minor, jasmonic acid, Real-time PCR.

\section{Introduction}

A complex mixture of volatile organic compounds (VOC) is released by the plants in response to various biotic and abiotic stresses. These complex VOC mixtures were found to act as attractant for pollinators (Raguso, 2008), serve as direct and indirect defenses against herbivores and involved in inter-plant communication (Hassan et al., 2015). A large proportion of these VOCs comprise of terpene compounds, which is the largest and the most diversified group of plant natural products. Currently, more than 50,000 terpenoids have been identified from both terrestrial and marine plants, animals, bacteria and fungi (Thoppil and Bishayee, 2011; Yamada et al., 2015). The basic building block of all natural terpenoids is an unsaturated pentahydrocarbon, known as isoprene unit. Terpenes can be classified, based on the number of isoprene units present in their basic skeleton, into monoterpenes (10C; e.g. Geraniol and $\delta$-limonene), sesquiterpenes ( $15 \mathrm{C}$; e.g. $\beta$-caryophyllene and $\delta$-cadinene), diterpenes (20C; e.g. Retinol) and so on (Thoppil and Bishayee, 2011). In plants, the biosynthesis of terpene compounds takes place by two distinct pathways, including the cytosolic mevalonate pathway and the plastidial MEP pathway. These two pathways are localized at different compartments of the cell and responsible for the biosynthesis of different classes of terpenes (Lichtenthaler et al., 1997).

In addition to their ecological functions, terpene compounds are also regarded as a group of natural products with great medicinal values. Recently, many studies have focused on the medicinal potential of terpene compounds for the prevention and therapy of several diseases, including cancer and tumor formation. Numerous terpene compounds have been identified with antimicrobial, antifungal, antiparasitic, antiviral, anti-allergenic, antispasmodic and anti-inflammatory properties (Aharoni et al., 2005). Pharmaceutical properties of terpene compounds have become one of the biggest attractions for their commercialization. Among them, artemisinin (antimalarial) and paclitaxel (anticancer) are some of the most prominent members of this class, which have been successfully proven for its value in modern pharmacotherapy and commercialization (Cragg and Newman, 2005). Traditionally, direct extraction of the valuable terpene compounds was employed from their natural sources (Wang et al., 2005). However, these extraction methods often encounter many problems, such as poor yields and the presence of impurities. Therefore, attempts were made to find feasible ways to enhance the production of terpenoids by manipulating the terpene biosynthetic pathway in microorganisms and plants. Manipulation of terpene production involved detailed analysis of the components in terpene biosynthetic pathway, especially at the genetic level. Among all the components of terpene biosynthesis pathway, terpene synthase gene is the most widely studied gene family. Numerous terpene-related studies have reported this aspect of the pathway because of its direct involvement in the conversion of precursors into various terpenoid structures, such as sesquiterpene skeleton (Degenhardt et al., 2009). By overexpressing the terpene synthase gene, many studies have achieved their goal of enhancing the production of desired terpene compounds in plants as well as in the microorganisms (Harada et al., 2009; Tsuruta et al., 2009; Liu et al., 2011). Therefore, studying the terpene synthase gene as well as its regulatory mechanism is very useful for designing a successful strategy of metabolite 
engineering for terpenoid biosynthesis in the plant species. $P$. minor, known as kesum in Singapore, Indonesia and Malaysia, is one of the herbaceous dicot plants belonging to the family Polygonaceae. Naturally, the plant has been found to release a sweet and pleasant aroma, which is strong enough to be detected by human nose. Currently, a multitude of structurally different sesquiterpenes have been identified from the essential oil of this plant. These sesquiterpene compounds include $\beta$-caryophyllene, $\alpha$-humulene, valencene, $\alpha$-bergamotene and others. In contrast to the metabolomics studies, only a single cDNA encoding terpene synthase has been identified and characterized from the $P$. minor plant. The terpene synthase (TPS) genes are usually present as a multi-gene family in higher plants. For example, 32 and 152 TPS-like gene model have been identified from the genomic DNA of Arabidopsis thaliana (Aubourg et al., 2002) and Vitis vinifera (Martin et al., 2010), respectively. Therefore, most probably more TPS genes remained to be identified and characterized from this plant. Jasmonates is a class of plant hormones derived from a polyunsaturated fatty acid, called $\alpha$ linolenic acid, through the octadecanoid pathway (Kazan and Manners, 2008). In plants, this class of phytohormone plays an important role in mediating the plant response towards various environmental stresses (biotic and abiotic) by regulating the transcription level of stress-responsive genes. It has been well documented that exogenous application of jasmonates (i.e. jasmonic acid or methyl jasmonate) can induce a similar response to the elicited plants as do the endogenous jasmonate (Moore et al., 2003; Bruinsma et al., 2009; Kiers et al., 2010). Previous studies have shown that exogenous application of jasmonic acid on the in vitro culture of $P$. minor leads to a significant increase in the production of various secondary metabolites, especially sesquiterpenes (Ismail, 2011). Therefore, in the present study jasmonic acid elicitation of the $P$. minor plants followed by real time PCR was employed to investigate the influence of jasmonic acid treatment towards the expression level of PmSS gene.

\section{Results and Discussion}

\section{Molecular cloning of sesquiterpene synthase gene from Persicaria minor}

By using a pair of degenerate primer, one partial cDNA sequence with the size of $500 \mathrm{bp}$ was cloned from the leaf samples of $P$. minor (data not shown). Due to its high degree of homology with the extant plant sesquiterpene synthase gene, RACE-PCR was then performed to isolate the complete sequence of the partial cDNA sequence. The complete sequence of the isolated gene, designated as PmSS, is composed of 1978 nucleotides, which includes an open reading frame (ORF) of 1680 nucleotides, encoding a polypeptide of 559 amino acids. This sequence was recorded in Genbank (KT192706). The deduced protein sequence of PmSS was predicted to possess a molecular weight of 64.6 $\mathrm{kDa}$ and theoretical isoelectric point value of 6.11 . Comparative sequence analysis on the complete sequence of PmSS exhibited a very high degree of homology $(98 \%$ identity) with a drimenol synthase gene from Persicaria hydropiper. High amino acid conservation suggested that the protein encoded by PmSS may also function as a drimenol synthase in Persicaria minor. Other sesquiterpene synthase genes which shared a moderate homology with PmSS include germacrene A synthase (51\% identity, 96\% coverage, $\mathrm{E}=0$ ) and $\delta$-cadinene synthase (50\% identity, $69 \%$ coverage, $\mathrm{E}=0$ ) from Vitis vinifera and Theobroma cacao, respectively.
Subcellular localization prediction of PmSS using WoLF PSORT suggested that PmSS is a cytosolic protein and it has been supported by the absence of signaling peptide on its protein sequence. Comparative sequence analysis, prediction of physicochemical properties and subcellular localization of PmSS have all reached to a common ground that it might encode for a sesquiterpene synthase. Subcellular localization prediction of PmSS using WoLF PSORT suggested that PmSS is a cytosolic protein and it has been supported by the absence of signaling peptide on its protein sequence. Several common features of sesquiterpene synthase have been reviewed by some previously published articles (Bohlmann et al., 1998; Cheng et al., 2007; Degenhardt et al., 2009). Generally, sesquiterpene synthase is a globular protein that is hydrophilic in nature and localized in the cytosolic compartment of the plant cell. Compared with the plastidial terpene synthase such as monoterpene synthase, sesquiterpene synthase is smaller in size (530-600 a.a) due to the absence of signal peptide at its $\mathrm{N}$-termini. Hence, comparative sequence analysis, prediction of physicochemical properties and subcellular localization of PmSS have all reached to a common ground that it might encode for a sesquiterpene synthase. Multiple sequence alignment of deduced protein sequence of PmSS gene with selected sesquiterpene synthase protein sequence available in GenBank (Fig. 1) had also revealed that the protein sequence of PmSS contains several highly conserved regions in the terpene synthase, such as the aspartate-rich metal ion binding site known as DDxxD (position 311-315). DDxxD motif can be found in almost all of the reported plant terpene synthases and responsible for the divalent metal ion $\left(\mathrm{Mg}^{2+}\right.$ and $\left.\mathrm{Mn}^{2+}\right)$ binding, which in turn, facilitates the binding of substrate. Another motif which is known as NSE/DTE $[(\mathrm{N}, \mathrm{D}) \mathrm{D}(\mathrm{L}, \mathrm{I}, \mathrm{V}) \mathrm{X}(\mathrm{S}, \mathrm{T}) \mathrm{XXXE}]$ has also been identified on the deduced amino acid sequence of PmSS at the position of $456^{\text {th }}-464^{\text {th }}$ amino acid residues. Similar as DDxxD motif, NSE/DTE is also a metal binding motif involved in the coordination of the metal ion for the fixation of pyrophosphate substrates (Degenhardt et al., 2009). Besides that, another two conserved motifs can also be found from PmSS, which are $\mathrm{RPX}_{8} \mathrm{~W}$ (position 263-273) (Bohlmann et al., 1998) and RXR (position 264-266) (Stark et al., 1997).

\section{Phylogenetic analysis}

A phylogenetic tree has been reconstructed using amino acid sequence of PmSS and 43 biochemically characterized terpene synthase using neighbor-joining method. According to the classification proposed by Bohlmann et al. (1998), terpene synthase can be divided into 6 different subfamily of terpene synthase (TPS-a - TPS-f) based on the amino acid sequence relatedness. Terpene synthases, which are sharing a minimum of $40 \%$ identity, will be grouped into the same subfamily under this classification. Recently, another group of Tps subfamily, designated as TPS-g, has been proposed by Dudareva (2003) after the discovery of three unique monoterpene synthases from snapdragon. Based on the classification above, the reconstructed phylogenetic tree was grouped into 7 different subfamilies and each monophyletic group was supported with bootstrap value of $100 \%$. In accordance with the phylogenetic relatedness, the TPSs in each subfamily displayed a clear distinction from the member of other subfamilies. Among them, TPS-c and TPS-e subfamilies comprised of terpene synthases involving in the primary metabolisms e.g. copalyl synthase and ent-kaurene synthase. TPS-f was represented by a single S-linalool synthase from Clarkia breweri, while TPS-d subfamily 
ADR66821.1 XP_007021123.1 BĀ 74389.1

NP 001268215.1 AE $\bar{P} 17005.1$ NP_001268213.1 PmSS

ADR66821.1 XP_007021123.1 BA $\bar{P} 74389.1$

NP 001268215.1 AE $\bar{P} 17005.1$ NP_001268213.1 PmSS

ADR66821.1 XP_007021123.1 BĀ 74389.1 NP 001268215.1 AE $\bar{P} 17005.1$ NP_001268213.1 PmSS

ADR66821.1 XP 007021123.1 BĀ 74389.1 NP 001268215.1 AE $\bar{P} 17005.1$ NP_0 01268213.1 PmSS

ADR66821.1 XP 007021123.1 BĀP74389.1 NP 001268215.1 AE $\bar{P} 17005.1$ NP_001268213.1 PmSS

ADR66821.1 XP 007021123.1 BĀP74389.1 NP 001268215.1 AE $\bar{P} 17005.1$ NP_001268213.1 PmS $\bar{S}$

ADR66821.1 XP 007021123.1 BĀP 74389.1 NP 001268215.1 AEP17005.1 NP_001268213.1 PmSS
MSIOVSTCPLVOIP ... KPEHRPMAEFHPS IWGDOFIAYTPEDEDTRACKEKOVEDLKAEVRRELMAAAG . N . PAOLLNFID MSS LASSSLPVSTNDSMSNENRRSTKFHPS IWGDLFLSFPSKVN . VDTTTQLHYEELKQEVRRMLRVPTDNQ . . LSQKLRLIE MSFAVSASPAKVIQNAGKDTTRRSANFHPS IWGDHFLQYTCDSQEPDDGSNVKHLELKKEIR. RMLKADNK . . PSRTLELID MSTOVSASSLAQI P... QPKNRPVANFHPNIWGDQFITYTPEDKVTRACKEEQIEDLKKEVKRKLTAAAVAN . . PSQLLNFID MSVQSSVVLLAPSKNLSPEVGRRCANFHP S IWGDHFLSYASEFTNTDDHLKQHVQQLKEEVR. KMLMAADDD . . SAQKLLLID MSVQSS GVLLAP SKNLS PEVGRRCANFHPS IWGDHFLSYASEFTNTDDHLKQHVQQLKEEVR . KMLMAADDD . . SAQKLLLID ..MSTAVNVPSAVR . . PADKRPIASFHPSPWGDYFLKYVPCDQVTQAKMEDEVKKVEEDVKKELRKLAKAVGKPLELLNFID

AVQRLGVAYHFEREIEESLOHIYDRFHD . . ADDTEDDLYNIALQFRLLRQQGYNISCGIFNKFKDEKGSFKEDLISNVQGMT TIKRLGVSYHFERE IEDVLQNIYDQD . . . . . . YKDDNLEVTSLRFRLLREHGFNVQCETFNKFKDDKGNFKVSLKSDVKGLL AIQRLGVSYHFESEIDEILGRVHQAYQES DLCVNENDGLYY I SLQFRLLRENGYRI SADVFNKFRDI DGNFKPSLAKDVRGMI AVORLGVAYHFEOE IEEALQH ICNSFHD . . CNDMDGDLYNIALGFRLLRQQGYT I SCDIFNKFTDERGRFKEALISDVRGMI AIQRLGVAYHFESE IDEVLKHMFDGS . . . . .VVSAEEDVYTASLRFRLLRQQGYHVSCDLFNNFKDNEGNFKESLSSDVRGML AIQRLGVAYHFESEIDEVLKHMF DGS . .... VVSAEEDVYTASLRFRLLRQQGYHVSCDLFNNFKDNEGNFKESLSSDVRGMI VVERLGVGYRLEQEIEDLVQTIFDNDK . . . . FGVHEFDLYHTSLWFRLLRQHGFHVSCDVFGKFKGKNARFKDSLASDVKGIL

GLYEAAHLRVHGEDTLEEALAFTTTHLKATVESLGY. PLAEOVAHALKHPIRKGLERLEARWY ISLYODEASHDKTLLKLAKI ELYEAAHIRTHGEH ILEEALAFTTTHLESAKTSLCEY P ISVLVSHARKRPIRKGLQRLEARRF IS IYQEDGSHDKTLLKFAKI SLYEATHLRVHEENI L DEAHAFATSHLESIATHQISSPLAEQVKHALFQP I HKGVQRLEARHY IS IYREESSHNEALLTFAKI GLYEAAHLRVHGEDI LAKALAFTTTHLKAMVES LGY. HLAEOVAHALNRPIRKGLERLEARWY ISVYODEAFHDKTLLELAKI SSYEATHFRVHGEDILDEALAFTTTHLQSATKYSSN. PLAEQVVHALKQPIRKGLPRLEARHYFSVYQAYDSHNKALLKLAKI SLYEATHFRVHGEDILDEALAFTTTHLQSATKHSSN. PLAEQVVHALKQPIRKGLPRLEARHYFSVYQADDSHNKALLKLAKI GLYEASHVRTHGDDTLDEALVFTTTHLKAVVTNQPNHPLVSQVTHALMQPYHKGMPRLESRHFIAFYEKDPYHDKTLLKFGKL

QPFTEAIERWDIKSIDHLPEYMKLFYVTLLDLYKEIDQELEKYGNQYRVYYAKEVLKSQVRAYFAEAKWSHEGYIPTIEEYML QLFTKAIERWDTNCMDRLPAYMKLFYKALLDVYEEMEEVMTKQVKSYRVKYAKEAMKQLSQAYFVEAKWYHENYVPTVEEYMT ELFTSAIERWDISAIDELPEYMKLCYRALLDVYSEAEKDLASQGKLYHLHYAKEAMKNQVKNYFFEAKWCHQNYIPSVDEYMT KLFIEAIERWDINS INOL PEYMKLCYVALLDVYKE IEEEMEKEGNOYRVHYAKEVMKNOVRAYFAEAKWLHEEHVPAFEEYMR ELFTEAVERWDISAIDQLPEYMRVCYQALLYVYSEIEEEMAREGRSYRLYYAKEAMKNQVRAYYEEAKWPQVQQIPTMEEYMP ELFTEAVERWDISAIDQLPEYMRVCYQALLYVYSEIEEEMAKEGRSYRLYYAKEAMKNQVRAYYEEAKWLQVQQIPTMEEYMP TAFTKAAERWDHSCLDELPDYMKVSYASLIDTFEEFERDLAPQGRSWSVKYAREEMIQMCRVYYQEAKWCHEKYSPTCDEYLE

VALVTSGSCILATWSF I GMGE IMTKEAFDWVISDPKI ITASTVIFRLM NDITTHKFE OKRGHVASGIECYMKOYGVSEEQVY . NALVSSGYIMVTVTSFVGMGNVVTKETFQWASNNPRIVRASS I IARLMDDIVSHKF EERGHVASA IECYMKQHGVSEEKAC .VASVTSGYPMLSTTSFVGMGDIVTKESFEWSLTNPRVIRASSVAARLMNDMVSHKFE SSRGHVASCVECYIKQYGATEEEAC . VALASSGYCLLATTSFVGMGE IATKEAFDWVTSDPKIMS S SNF I TRLMDDIKSHKFE OKRGHVASAVECYMKQYGVSEEQVY .VALVTSAYSMLATTSFVGMGDALTKETLDWIFSEPKIVRASAIVCRLMDDMVPHKFEQKRGHVASAVECYMKQHGASEQETH . VALVTSAYSMLATTSFVGMGDAVTKESFDWIFSKPKIVRASAIVCRLMDMVFHKFF QKRGHVASAVECYMKQHGASEQETP KAS IVSFGYNLGTVVCF LGMGDVATKEAFEWARGNPKVVRAA GI I GRLM DDIGSHDFE QGRDHVPSAVECYIRQHGVDEVTAQ

SEFHKQVENAWLDINQECLKP. TAVPMPLLTRVVNLSRVMDVIYKEGDGYTHVGKVMKDNIGSVLIDPIV NELNKQ IENAWKDINQELVRPPAGVPMPVLTRI LNLARVMDFLYKEGDGYTHVGEAVKDGITSLMIDPIP NEFRKQVSNAWKDVNEECLRP. TVVPMPLLMRILNLTRFLDVVYRFEDGYTHSGVVLKDFVASLLINPVS SEFOKOIENAWLDINOECLKP. TAVSMPLLARLLNLTRTMDVIYKEODSYTHVGKVMRDNIASVFINAVI NEFNKQVRDAWKDINEECLIP. TAVPMP I LMRVLNLARVI DVIYKNEDGYTHSGTVLKDFVT SMLIDPVP NEFPQPVREAWKDINEECLIP. TAVPMPI LMRVLNLARVI DVIYKNEDGYTHFGAVLKDFVTSMLIDPVP RELGKRVESSWKDI SEMMLKP. YMMPKPLLTRI PNECRIVDVIYKGEDSYTFSTTTMKKNISH ILTDPIP

Fig 1. Multiple sequence alignment of PmSS and the other six homologous proteins. PmSS: the isolated sesquiterpene synthase protein sequence from P. minor. ADR 66821.1: Germacrene A synthase from Vitis vinifera. NP001268215.1: Valencene synthase from Vitis vinifera; AEP17005.1: (E)- $\beta$-caryophyllene synthase from Vitis vinifera. NP 001268213.1: (-)-Germacrene D synthase from Vitis vinifera. XP_007021123.1: $\delta$-cadinene synthase from Theobroma cacao. BAP74389.1: $\delta$-elemene synthase from Citrus jambhiri. The conserved amino acid regions are shown in the black column and labeled accordingly: NSE/DTE, RxR and DDxxD. Region underlined with black horizontal line represent the N-terminal domain, while region underlined with red horizontal line represents the C-terminal domain. 


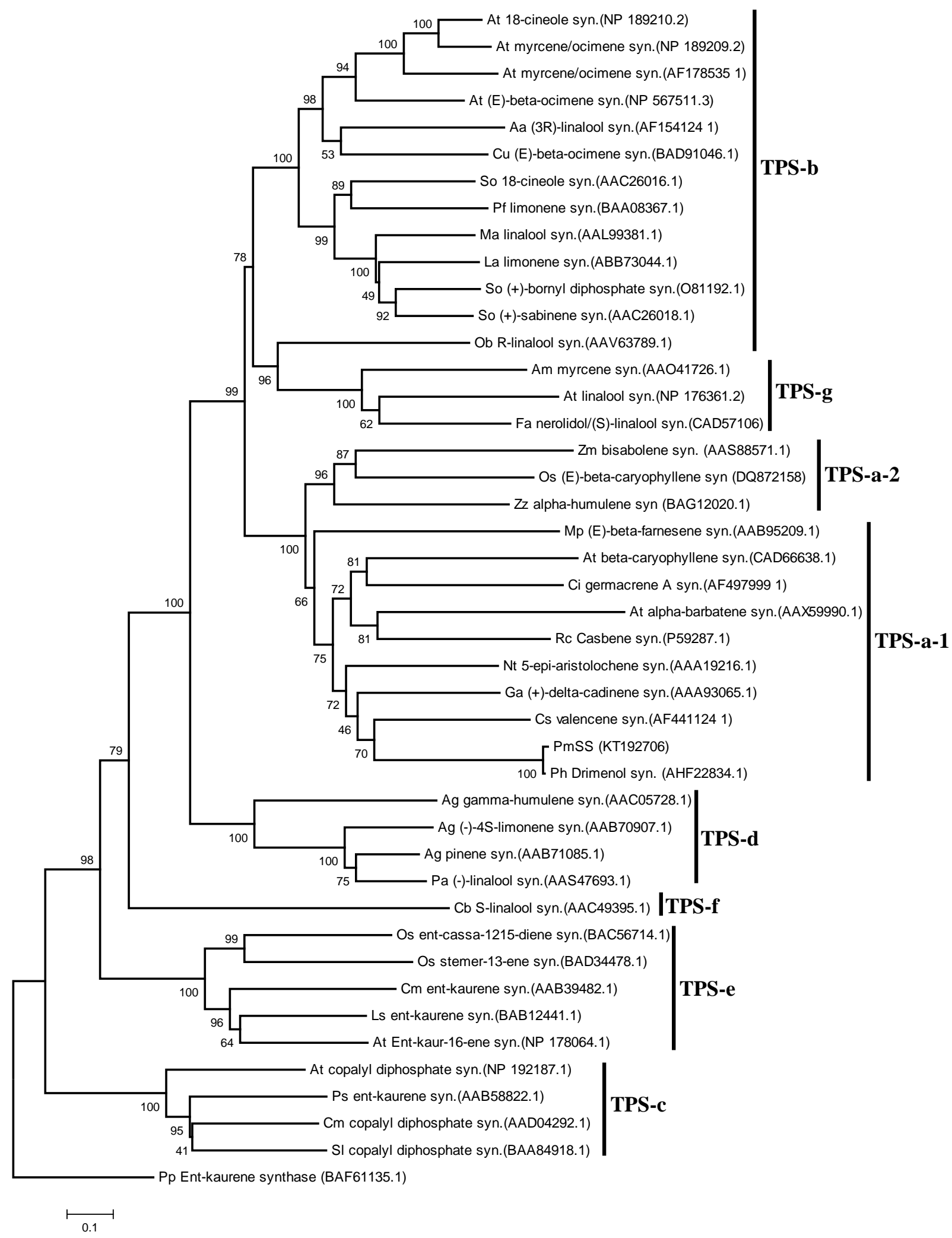

Fig 2. Reconstruction of phylogenetic tree of the isolated PmSS with selected biochemically characterized terpene synthase based on neighbour-joining method. The phylogenetic tree is divided into 7 group of terpene synthase (tpsa-tpsg) based on the sequence identity where the terpene synthase in each group are having at least $40 \%$ identity. The bootstrap value was set at 1000 replications. Most of the amino acid sequences were selected from Landmann et al. 2007 [37] to ensure the quality of the phylogenetic tree in this study. Ent-kaurene synthase (AB302933OS) from Physcomitrella patens subsp. patens was selected as the outgroup in the reconstructed phylogenetic tree. 


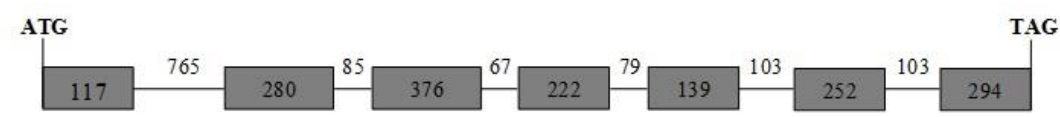

Fig 3. Schematic diagram of the organization of the genomic sequence for PmSS. Grey boxes represent exon sequences which are separated by introns. PmSS's genomic sequence is comprised of 7 exons and 6 introns which can be grouped as class III TPS based on the classification proposed by Trapp and Croteau (2001).

a)
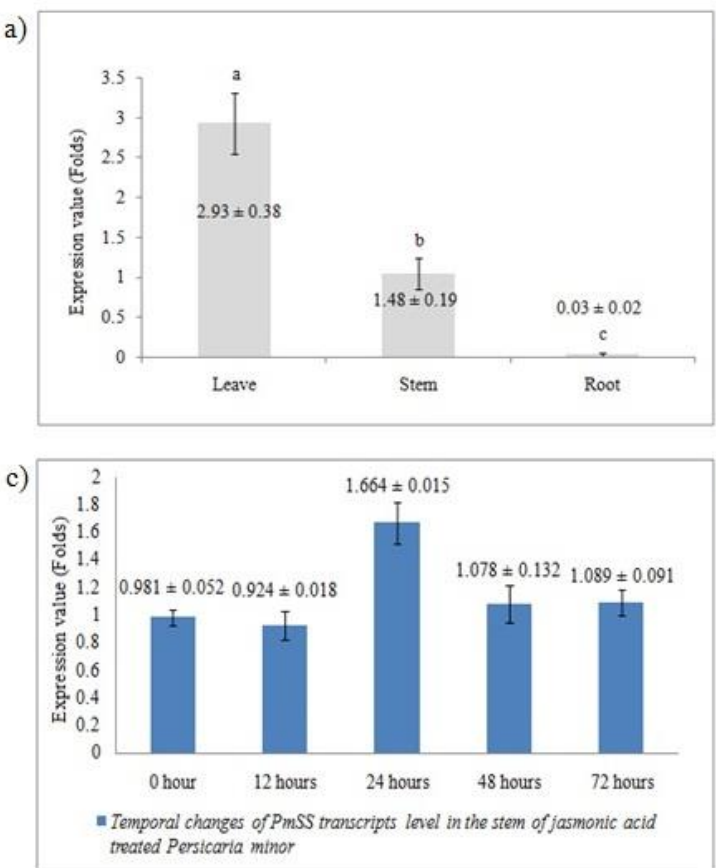

b)

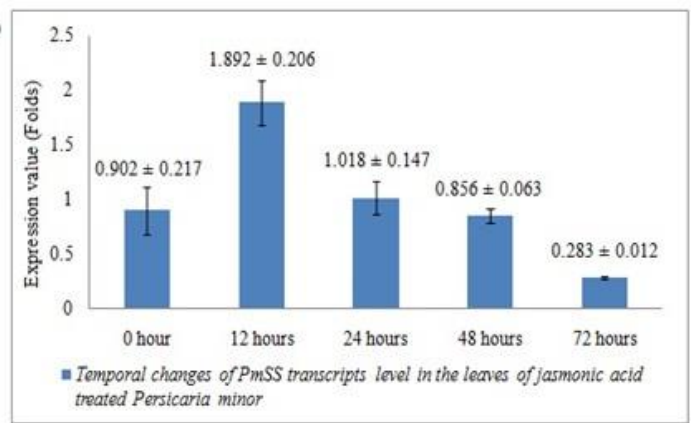

d)

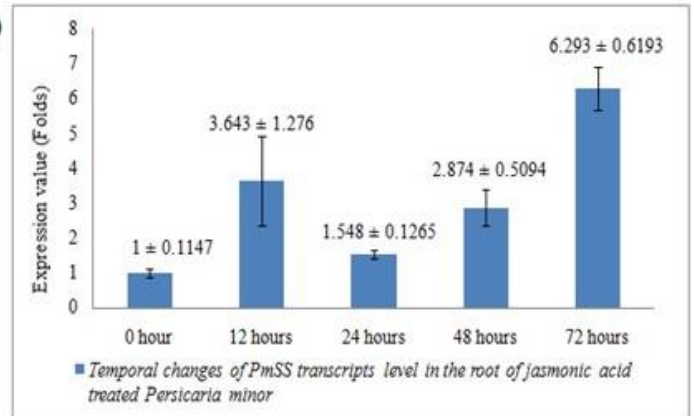

Fig 4. Expression pattern analysis of PmSS transcripts level. (a) Changes of PmSS transcript level at different organs. (b) Temporal changes of PmSS transcript level in the stem of jasmonic acid treated P. minor. (c) in the stem of jasmonic acid treated $P$. minor. d) in the root of jasmonic acid treated $P$. minor. The value of expression level were expressed as mean \pm standard deviation $(\mathrm{n}=3)$. Different alphabet $(\mathrm{a}-\mathrm{c})$ over the bars indicate significant difference at $\mathrm{P}<0.001$

represents gymnosperm specific terpene synthase of the specialized metabolism. On the other hand, TPS-a, TPS-b and TPS-g subfamilies represent angiosperm specific terpene synthase, which are involved in the specialized metabolism (Chen et al., 2011). Within the reconstructed phylogenetic tree, PmSS was grouped into the subfamily of TPS-a, which comprised mainly of sesquiterpene synthase from angiosperm. Within the subfamily of TPS-a, it can also be further divided into two sub-groups with sub-group TPS-a1 being dicotspecific, while sub-group TPS-a2 is monocot-specific (Jia, 2014). In the reconstructed phylogenetic tree, these two groups have been separated successfully with a bootstrap value of $100 \%$. The PmSS was observed to be located in the sub-group TPS-a1, which can be explained by the fact that $P$. minor is a flowering dicotyledonous plant (Fig. 2).

\section{Genomic organization}

In addition to the classification system through the sequence relatedness, another method for classifying different types of terpene synthase gene was proposed by Trapp and Croteau (2001). In their study, it was observed that terpene synthase appear to have evolved sequentially by introns loss of the conifer diterpene internal sequence domain. As a result, three distinct classes (class I-III) of terpene synthase have been defined, based on the number of introns and exons. In order to investigate the genomic organization of PmSS gene, the genomic sequence $(2.8 \mathrm{~kb})$ of $P m S S$ gene was obtained by PCR amplification using a pair of primers, flanking the open reading frame sequence of PmSS. The intron junction was then mapped by the alignment between the cDNA sequence and the genomic sequence (Fig. 3). It was observed that the intron-exon organization of PmSS genomic sequence resembled a typical class III TPS gene with 7 exons (1-117; $883-1162$; 1248-1623; 1691-1912; 1992-2130; 2234-2485; 2589-2882) segments interrupted by 6 introns (118-882; 1163-1247; 1624-1690; 1913-1991; 2131-2233; 2486-2588). A typical class III TPS gene encompasses the terpene synthase gene, which encodes angiosperm monoterpene, sesquiterpene and diterpene synthases involved in the specialized metabolism. Combining all the in silico analyses of $P m S S$, it is appropriate to predict that PmSS is encoding a drimenol synthase in $P$. minor.

\section{Expression level of PmSS in different plant tissues}

Quantitative real time PCR (qRT-PCR) analysis revealed that the transcript level of PmSS gene varied significantly among the different organs. As presented in Fig. 4(a), the transcript level of PmSS gene was significantly higher in the aerial organs of $P$. minor compared to the below-ground organ. Among the organs, leaf tissue of the $P$. minor was found to accumulate the highest amount of PmSS transcripts, which were approximately 98-folds higher than that of the root tissue. Second highest level of PmSS transcript was calculated in the stem tissue that was approximately 49 -folds higher than that of the root tissue.

The expression of terpene synthase gene can be either constitutive or inducible due to various stresses (Fontana et al., 2011). In the present study, all the in vitro cultures of $P$. 
minor were maintained in a controlled environment; therefore, the influence from the external factors such as wounding, herbivores and pathogens attack towards the gene expression of PmSS can be excluded. It means that the expression of $P m S S$, especially in the aerial organs of $P$. minor, were constitutive under the normal condition. Direct correlation between the accumulation of certain types of sesquiterpenes and the expression levels of their corresponding synthase genes have been reported by several previous studies (Köllner et al., 2008; Nagegowda, 2010). Therefore, it is reasonable to assume that the gene product of PmSS (putatively drimenol) was constantly synthesized by $P$. minor under the normal conditions. Generally, sesquiterpene compounds have two important roles in plants such as attraction of pollinators (Martin et al., 2009) and to defend plants from the attack of various predators (Bleeker et al., 2012). Higher expression level of PmSS in the vegetative tissues suggests that the protein is involved in the defense system of $P$. minor rather than the pollination. According to optimal defense hypothesis, parts of the plant with higher probability of being attacked by pests would have higher basal levels of specific defense metabolites (Meldau et al., 2012). Therefore, high amounts of the product of PmSS in the above-ground organs of $P$. minor is indicative of its role in the plant defense system for preventing herbivore attack or against certain fungal pathogens, which always attack on the above-ground organs of $P$. minor.

\section{Temporal analysis of PmSS expression level after JA elicitation}

The qRT-PCR was carried out to investigate the influence of jasmonic acid elicitation towards the expression of PmSS gene in different organs of $P$. minor at different time points. The expression pattern of PmSS gene, in different organs of $P$. minor at different time points, after jasmonic acid treatment are shown in Fig. 4(b), (c) and (d). These results show that the transcript level of PmSS gene, in $P$. minor increased significantly after the plants were sprayed with jasmonic acid solution. However, the maximum transcript level of PmSS, in different organs was reached at different time points. Among the organs studied, leaves and stem took a shorter time to reach its maximum level, which were 12 hours and 24 hours after jasmonic acid treatment, respectively. As compared with the leaves and stem, the transcript level of PmSS in roots took a relatively longer time to reach its highest level, which was 72 hours after jasmonic acid treatment. The difference may be due to spraying method adopted in the present study, in which the jasmonic acid solution was sprayed from the top of plantlets. As a consequence, the leaves and the stem were exposed to jasmonic acid solution at an earlier time than roots, which were covered underneath the media. In nature, endogenous jasmonic acid was found to induce the cellular response from the plant organs that are distant from their site of synthesis. Likewise, the enhanced gene expression level of $P m S S$ in the root may also be due to systemic defensive response in the roots, being triggered by exogenous jasmonic acid application on the aerial organs of $P$. minor. A similar response was also observed in the root of rice (Oryza sativa), after exogenous application of jasmonic acid on the shoots (Nahar et al., 2011). The transportation of exogenous jasmonic acid from the leaves to the roots has been proven by Zhang and Baldwin (1997), using radiolabeled jasmonic acid. According to this study, the radiolabeled jasmonic acid was found to be transported from the leaves into the roots of Nicotiana sylvestris and subsequently increased the production of nicotine within the root (Zhang and Baldwin, 1997).

By looking at the expression pattern of PmSS along with the time course of JA treatment, transcript level of PmSS started decreasing gradually towards its basal level after reaching the maximum expression. It indicated that a negative feedback control of jasmonate signaling was established at that time to attenuate JA response of $P m S S$ gene expression. The negative regulation of PmSS gene expression might be due to activation of JASMONATE ZIM DOMAIN PROTEIN (JAZ) dependent repression system (Acosta et al., 2013). Previous studies have shown that positively acting transcription factors, such as MYC or WRKY were inactivated by the binding of JAZ proteins under the normal conditions. Upon wounding, jasmonoyl-isoleucine accumulation leads to degradation of JAZ domain protein by $26 \mathrm{~S}$ proteasome pathway and the release of jasmonate-responsive transcription factors from the degraded JAZ domain protein. Consequently, the downstream jasmonate-responsive genes will be activated through the binding of JA-responsive transcription factors (Thines et al., 2007; Ge et al., 2015). In Arabidopsis thaliana, a gene (JAZ10) encoding JAZ repressor protein was found to be inducible by jasmonic acid treatment (Moreno et al., 2013). It means that the negative regulation of jasmonate signaling may also be activated at the same time during the jasmonic acid treatment. However, further studies are required to be carried out to verify the involvement of JAZ dependent repression system in the regulation of PmSS gene expression.

\section{Materials and Methods}

\section{Plant materials}

The in vitro culture of $P$. minor was originated from Malacca Biotechnology Institute (Malacca, Malaysia). For the purpose of micropropagation, the stem of $P$. minor was cut into segments containing two nodes. Each segment was then cultured on Murashige and Skoog's (MS) (Duchefa, Netherlands) medium (Murashige and Skoog, 1962), supplemented with $30 \mathrm{~g} \mathrm{l}^{-1}$ sucrose and then solidified with $0.3 \%$ gelrites. The $\mathrm{pH}$ of the MS medium was adjusted to 5.8 with $1 \mathrm{M} \mathrm{NaOH}$. It was then grown in a growth chamber at $25 \pm 2{ }^{\circ} \mathrm{C}$ with a photoperiod of $16 \mathrm{~h}$ light $/ 8 \mathrm{~h}$ dark and subcultured once every 2 months. The leaf samples were harvested from in vitro culture of $P$. minor plantlets after been sub-cultured for 2 months.

\section{mRNA isolation and cDNA synthesis}

Total RNA was extracted from $5 \mathrm{~g}$ of the harvested leaf material using modified López-Gómez total RNA extraction method (López-Gómez and Gómez-Lim, 1992). From $1 \mu \mathrm{g}$ of total RNA, mRNA was isolated through PolyATract ${ }^{\circledR}$ mRNA Isolation System III (PROMEGA). cDNA was then generated through SuperScript ${ }^{\circledR}$ III Reverse transcriptase (Invitrogen Corp., Carlsbad, CA) according to the manufacturer's protocol.

\section{Molecular cloning of PmSS}

The partial sequence of sesquiterpene synthase gene from $P$. minor cDNA was amplified by a pair of degenerate primers (Forward: 5' AAGTTGGACTTYAAYYTYYTBCA 3'; Reverse: 5' CTATGTGCCNATRCGNCTR 3'). Degenerate PCR was carried out using Advantage 2 PCR enzyme mix (Clontech) in a total reaction volume of $25 \mu$ l with the following cycling parameters: Initial denaturation at $95^{\circ} \mathrm{C}$ for 
3 minutes, followed by 25 cycles of denaturation at $95^{\circ} \mathrm{C}$ for $45 \mathrm{~s}$, annealing at $50^{\circ} \mathrm{C}$ for $30 \mathrm{~s}$, extension at $72^{\circ} \mathrm{C}$ for $90 \mathrm{~s}$ and final extension at $72^{\circ} \mathrm{C}$ for 10 minutes. PCR products were gel-purified, cloned into pGEM-T-easy vector (Promega) and sequenced. Rapid amplification of cDNA ends PCR was then performed to obtain the complete sequence of the putative sesquiterpene synthase gene through SMARTer ${ }^{\mathrm{TM}}$ RACE cDNA amplification kit (Clontech). The gene specific primer for 5'RACE was 5'-CTCTGCTCGGGAAAGGCATCTTCG3' while the primer sequence used for 3'RACE was 5'CGCAAATTGGACTTCAACTTGGTGC-3'. The DNA sequences obtained from 5'RACE and 3'RACE PCR were then aligned and assembled through BioEdit Sequence Alignment Editor (Version 7.0.9.0) to get the complete sequence. A pair of gene specific primers (Forward: 5'TCGACCACCGGCCA TGTCTACTGC-3'; Reverse: 5'CCTAAATCGGAATGGGATCGGTGAGA-3') were then designed to amplify the complete sequence of the gene from the cDNA of $P$. minor.

\section{In silico sequence analysis of PmSS}

The open reading frame of PmSS was located through an online bioinformatics tool called ORF Finder (http://www.ncbi.nlm.nih.gov/gorf/gorf.html). The nucleotide sequence comparison of PmSS was done using BlastX through NCBI website (http://blast.ncbi.nlm.nih. gov/Blast.cgi). The conserved domains of the protein sequence were analyzed through NCBI Batch CD-Search Tool. WoLF PSORT (http://wolfpsort.org/) and SignalP 4.0 (http://www.cbs.dtu.dk/services/SignalP/) were used to predict the localization and the presence of signal peptide. Multiple sequence alignment of deduced amino acid sequence of PmSS was also done against the other sesquiterpene synthase from NCBI GenBank database through ClustalW2 with default parameters (http://www.ebi. ac.uk/Tools/services/web_clustalw2/toolform.ebi). Neighborjoining analysis was used to construct a phylogenetic tree with 1000 replicates through MEGA 4 software.

\section{Genomic DNA isolation}

Genomic DNA was extracted from in vitro culture of $P$. minor through CTAB based genomic DNA extraction method (Doyle and Doyle, 1987). A pair of gene specific primers (gDNA fwrd: 5'-TCGACCACCGGCCATGTCTACTGC-3'; gDNA_rvrd: 5'-CCTAAATCGGAATGGGATCGGTGAGA-3') was designed to isolate the genomic DNA, which corresponds to the cDNA sequence of PmSS. The PCR reaction was carried out using Advantage 2 PCR enzyme mix (Clontech) in a total reaction volume of $25 \mu$ with the following cycling parameters: Initial denaturation at $95^{\circ} \mathrm{C}$ for 3 minutes, 25 cycles of $95^{\circ} \mathrm{C}$ for $45 \mathrm{~s}, 60^{\circ} \mathrm{C}$ for $30 \mathrm{~s}, 72^{\circ} \mathrm{C}$ for 90 s, and final extension at $72^{\circ} \mathrm{C}$ for 10 minutes.

\section{Expression profiling of PmSS at different organs}

Total RNA was extracted from different tissues of $P$. minor (roots, stems and leaves) as described above. Genomic DNA of the extracted total RNA was removed using Turbo DNAfree (Ambion, Inc.). After the removal of genomic DNA, Total RNA $(1 \mu \mathrm{g})$ was then reverse transcribed with iScript ${ }^{\mathrm{TM}}$ cDNA synthesis kit (Bio-rad, USA) in a total volume of $20 \mu 1$. The qRT-PCR was done using BioRad IQ5 instrument (Bio$\mathrm{rad})$ and the amplifications were performed in a $15 \mu \mathrm{l}$ reaction containing $\mathrm{iTaq}^{\mathrm{TM}}$ Universal $\mathrm{SYBR}^{\circledR}$ Green Supermix (Bio-Rad), $90 \mu \mathrm{M}$ of specific primers and $45 \mathrm{ng}$ of
cDNA. The amplification conditions were set as follows: 1 cycle of $95^{\circ} \mathrm{C}$ for $30 \mathrm{~s}, 40$ cycles of $95^{\circ} \mathrm{C}$ for $15 \mathrm{~s}$ and $55^{\circ} \mathrm{C}$ for 30s. Dissociation curve was established at the end of each run to check the specificity of amplification. For each tissue, three independent biological replicates were used for realtime PCR analysis. Primer efficiencies were calculated using the standard curves generated by five different concentrations of cDNA prepared from four-fold serial dilution. The expression level of PmSS was then normalized against two housekeeping genes, including $\alpha$-tubulin and $\beta$-actin.

\section{Jasmonic acid elicitation study}

Two-month-old in vitro culture of $P$. minor plantlets were treated with $5 \mathrm{ml}$ of $150 \mu \mathrm{M}$ jasmonic acid solution through spraying method. The JA-treated plantlets were then harvested at the intervals of 0 hour, 12 hours, 24 hours, 48 hours and 72 hours after the treatment followed by qRT-PCR analysis. Each experiment was carried out in triplicates.

\section{Statistical analysis}

Data were presented as the mean \pm SE. One-way ANOVA and Duncan multiple range test (DMRT) was done through statistical analysis software system (SAS) to assess the statistical significance of differences between organs at $\mathrm{P}<$ 0.001 .

\section{Conclusion}

A cDNA sequence (PmSS) from $P$. minor was successfully cloned and characterized. The entire in silico analyses on the sequence of PmSS, including physicochemical analysis, multiple sequence alignment, localization analysis and genomic organization, have suggested that it encodes a drimenol synthase. The qRT-PCR analysis showed that the expression of PmSS gene was differentially regulated among different organs of $P$. minor under the normal conditions. Besides that, the expression of PmSS also appeared to be regulated by the jasmonic acid signaling pathway as shown by the results of jasmonic acid elicitation experiments. The present study provides fundamental information about this putative sesquiterpene synthase gene that may serve as basic foundation for a more detailed investigation for the role of, as well as the regulation of its production in the $P$. minor.

\section{Acknowledgements}

This study was supported by National University of Malaysia (UKM) Research University grant AP-2014-003. Mr. Chew Jin Kiat was supported by National Science Foundation fellowship from Ministry of Science, Technology and Innovation of Malaysia.

\section{References}

Acosta IF, Gasperini D, Chételat A, Stolz S, Santuari L, Farmer EE (2013) Role of NINJA in root jasmonate signaling. Proc Natl Acad Sci USA. 110(38):15473-15478.

Aharoni A, Jongsma MA, Bouwmeester HJ (2005) Volatile science? Metabolic engineering of terpenoids in plants. Trends Plant Sci. 10(12):594-602.

Aubourg S, Lecharny A, Bohlmann J (2002) Genomic analysis of the terpenoid synthase (AtTPS) gene family of Arabidopsis thaliana. Mol Genet Genomics. 267(6):730745 . 
Bohlmann J, Meyer-Gauen G, Croteau R (1998) Plant terpenoid synthases: molecular biology and phylogenetic analysis. Proc Natl Acad Sci USA. 95(8):4126-4133.

Bleeker PM, Mirabella R, Diergaarde PJ, VanDoorn A, Tissier A, Kant MR, Prins M, de Vos M, Haring MA, Schuurink RC (2012) Improved herbivore resistance in cultivated tomato with the sesquiterpene biosynthetic pathway from a wild relative. Proc Natl Acad Sci USA. 109(49):20124-20129.

Bruinsma M, Posthumus MA, Mumm R, Mueller MJ, van Loon JJA, Dicke M (2009) Jasmonic acid-induced volatiles of Brassica oleracea attract parasitoids: effects of time and dose, and comparison with induction by herbivores. J Exp Bot. 60(9):2575-2587.

Chen F, Tholl D, Bohlmann J, Pichersky E (2011) The family of terpene synthases in plants: a mid-size family of genes for specialized metabolism that is highly diversified throughout the kingdom. Plant J. 66(1):212-229.

Cheng AX, Lou YG, Mao YB, Lu S, Wang LJ, Chen XY (2007) Plant terpenoids: biosynthesis and ecological functions. J Integr Plant Biol. 49(2):179-186.

Cragg GM, Newman DJ (2005) Biodiversity: A continuing source of novel drug leads. Pure Appl Chem. 77(1):7-24.

Degenhardt J, Köllner TG, Gershenzon J (2009) Monoterpene and sesquiterpene synthases and the origin of terpene skeletal diversity in plants. Phytochemistry. 70(15):1621-1637.

Doyle JJ, Doyle JL (1987) A rapid DNA isolation procedure for small quantities of fresh leaf tissue. Phytochem Bull. 19:11-15.

Dudareva N (2003) (E)-beta-ocimene and myrcene synthase genes of floral scent biosynthesis in snapdragon: Function and expression of three terpene synthase genes of a new terpene synthase subfamily. Plant Cell. 15(5):1227-1241.

Fontana A, Held M, Fantaye CA, Turlings TC, Degenhardt J, Gershenzon J (2011) Attractiveness of constitutive and herbivore-induced sesquiterpene blends of maize to the parasitic wasp Cotesia marginiventris (Cresson). J Chem Ecol. 37(6):582-591.

Ge Q, Zhang Y, Hua WP, Wu YC, Jin XX, Song SH, Wang ZZ (2015) Combination of transcriptomic and metabolomic analyses reveals a JAZ repressor in the jasmonate signaling pathway of Salvia miltiorrhiza. Sci Rep. 5:14048.

Harada H, Yu F, Okamoto S, Kuzuyama T, Utsumi R, Misawa N (2009) Efficient synthesis of functional isoprenoids from acetoacetate through metabolic pathwayengineered Escherichia coli. Appl Microbiol Biot. 81(5):915-925.

Hassan MN, Zainal Z, Ismail I (2015) Green leaf volatiles: biosynthesis, biological functions and their applications in biotechnology. Plant Biotechnol J. 13(6):727-739.

Ismail I, Gor MC, Mohamed-Hussein ZA, Zainal Z, Noor NM (2011) Alteration of abiotic stress responsive genes in Polygonum minus roots by jasmonic acid elicitation. In: Vasanthaiah $\mathrm{H}$ (ed) Plants and Environment. In Tech.

Jia W, Wang Y, Yu X, Zhang L, Liu S, Huang Z (2014) Characterization of terpene synthase gene family in 'Artemisia annua' L. Plant Omics. 7(5):373-381.

Kazan K, Manners JM (2008) Jasmonate signaling: toward an integrated view. Plant Physiol. 146(4):1459-1468.

Kiers ET, Adler LS, Grman EL (2010) Manipulating the jasmonate response: How do methyl jasmonate additions mediate characteristics of aboveground and belowground mutualism? Funct Ecol. 24(2):434-443.

Köllner TG, Held M, Lenk C, Hiltpold I, Turlings TC, Gershenzon J, Degenhardt J (2008) A maize (E)- $\beta$ caryophyllene synthase implicated in indirect defense responses against herbivores is not expressed in most American maize varieties. The Plant Cell. 20(2):482-494.

Lichtenthaler HK, Rohmer M, Schwender J (1997) Two independent biochemical pathways for isopentenyl diphosphate and isoprenoid biosynthesis in higher plants. Physiol Plantarum. 101(3):643-652.

Liu B, Wang H, Du Z, Li G, Ye H (2011) Metabolic engineering of artemisinin biosynthesis in Artemisia annua L. Plant Cell Rep. 30(5):689-694.

López-Gómez R, Gómez-Lim MA (1992) A method for extracting intact RNA from fruits rich in polysaccharides using ripe mango mesocarp. HortScience. 27(5):440-442.

Martin DM, Toub O, Chiang A, Lo BC, Ohse S, Lund ST, Bohlmann J (2009) From the cover: the bouquet of grapevine (Vitis vinifera L. cv. Cabernet Sauvignon) flowers arises from the biosynthesis of sesquiterpene volatiles in pollen grains. Proc Natl Acad Sci USA. 106(17):7245-7250.

Martin DM, Aubourg S, Schouwey MB, Daviet L, Schalk M, Toub O, Lund ST, Bohlmann J (2010) Functional annotation, genome organization and phylogeny of the grapevine (Vitis vinifera) terpene synthase gene family based on genome assembly, FLcDNA cloning and enzyme assays. BMC Plant Biol. 10:226.

Meldau S, Erb M, Baldwin IT (2012) Defence on demand: mechanisms behind optimal defence patterns. Ann Bot. 110(8):1503-1514.

Moore JP, Paul ND, Whittaker JB, Taylor JE (2003) Exogenous jasmonic acid mimics herbivore-induced systemic increase in cell wall bound peroxidase activity and reduction in leaf expansion. Funct Ecol. 17(4):549-554.

Moreno JE, Shyu C, Campos ML, Patel LC, Chung HS, Yao J, He SY, Howe GA (2013) Negative feedback control of jasmonate signaling by an alternative splice variant of JAZ10. Plant Physiol 162(2):1006-1017.

Murashige T, Skoog F (1962) A revised medium for rapid growth and bio assays with tobacco tissue cultures. Physiol Plantarum. 15(3):473-497.

Nagegowda DA (2010) Plant volatile terpenoid metabolism: Biosynthetic genes, transcriptional regulation and subcellular compartmentation. FEBS Lett. 584(14):29652973.

Nahar K, Kyndt T, De Vleesschauwer D, Höfte M, Gheysen $\mathrm{G}$ (2011) The jasmonate pathway is a key player in systemically induced defense against root knot nematodes in rice. Plant Physiol. 157(1):305-316.

Raguso RA (2008) Wake up and smell the roses: The ecology and evolution of floral scent. Annu Rev Ecol Evol S. 39(1):549-569.

Starks CM, Back K, Chappell J, Noel JP (1997) Structural basis for cyclic terpene biosynthesis by tobacco 5-epiaristolochene synthase. Science. 277(5333):1815-1820.

Thines B, Katsir L, Melotto M, Niu Y, Mandaokar A, Liu G, Nomura K, He SY, Howe GA, Browse J (2007) JAZ repressor proteins are targets of the $\mathrm{SCF}^{\mathrm{COI} 1}$ complex during jasmonate signalling. Nature. 448(7154):661-665.

Thoppil RJ, Bishayee A (2011) Terpenoids as potential chemopreventive and therapeutic agents in liver cancer. World J Hepatol. 3(9):228-249.

Trapp SC, Croteau RB (2001) Genomic organization of plant terpene synthases and molecular evolutionary implications. Genetics. 158(2):811-832.

Tsuruta H, Paddon CJ, Eng D, Lenihan JR, Horning T, Anthony LC, Regentin R, Keasling JD, Renninger NS, Newman JD, Gregson A (2009) High-level production of amorpha-4,11-diene, a precursor of the antimalarial agent artemisinin, in Escherichia coli. PLoS One. 4(2):e4489. 
Wang G, Tang W, Bidigare RR (2005) Terpenoids as therapeutic drugs and pharmaceutical agents. In: Zhang L, Demain AL (eds) Natural products: drug discovery and therapeutic medicine. Human Press, Totowa, NJ, pp $197-$ 227.

Yamada Y, Kuzuyama T, Komatsu M, Shin-Ya K, Omura S, Cane DE, Ikeda H (2015) Terpene synthases are widely distributed in bacteria. Proc Natl Acad Sci USA. 112(3):857-862.

Zhang ZP, Baldwin TI (1997) Transport of $\left[2-{ }^{14} \mathrm{C}\right]$ jasmonic acid from leaves to roots mimics wound-induced changesin end ogenous jasmonic acid pools in Nicotiana sylvestris. Planta.203(4):436-441. 